\title{
Constituição e mercado: entre o débâcle e a (re)afirmação
}

\section{José Querino Tavares Neto*}

\author{
O homem é a medida de todas as coisas: das coisas que são \\ enquanto são, das coisas que não são enquanto não são. \\ Protágoras de Abdera
}

\begin{abstract}
Sumário: Introdução; 1. Perspectiva metodológica; 2. Direito e mercado: um novo ethos desencantado; 3. Globalização e direito constitucional; 4. Constituição: Resistir é preciso, viver não é preciso. Considerações finais. Referências.
\end{abstract}

\begin{abstract}
Resumo: O Estado Constitucional, em face da constante e predatória interferência do mercado em âmbito local, regional e global, passa por um processo revisório de sua natureza e finalidade. A economia de mercado altera o centro decisório político, antes concentrado no Estado-nação, para o sistema financeiro internacional, não apenas restringindo seu grau de interferência, mas, sobretudo, delimitando e subordinando suas finalidades de gestão. Assim, merece olhar atento a necessidade de um processo revisional da categoria de Estado-nação enquanto sustentáculo de cartas políticas à luz da nova ordem global, sobretudo sua contribuição como legítimo representante da sociedade, não estando este subordinado, mas se traduzindo em ator principal, ao lado da sociedade civil local e global. Finalmente é necessário e imperativo, a partir do Estado-nação como interlocutor, inverter o processo regulatório do mercado em favor dos interesses da sociedade.
\end{abstract}

Palavras-chave: Estado, Mercado, Globalização, Constituição.

\begin{abstract}
The State Constitution, in the face of constant interference and predatory market in scope local, regional and global, through a process revisório of its nature and purpose. The market economy changes the political decision making centre, before concentrated in the nation-state for international financial system, not only restricting their degree of interference, but delimiting and subordinating their management purposes. This way, deserves careful look at the need for a process revisionary category of the nation state as a cornerstone of letters policies in the light of the new global order, especially its contribution as the legitimate representative of society, not this subject, but beside the main actor Civil Society local and global. Finally it is necessary and imperative, from the nation-state fas a partner in reversing the process by the market regulatory interests of society.
\end{abstract}

Keywords: State, Market, Globalization, Constitution.

\footnotetext{
* Mestre pela Unicamp, Doutor pela UNESP/Araraquara, professor-adjunto da Faculdade de Direito da Universidade Federal de Goiás, do Mestrado em Direito da UNAERP, do Mestrado em Desenvolvimento Regional das Faculdades ALFA, pós-doutor em Direito Constitucional na Universidade de Coimbra com bolsa da Capes.
} 


\section{Introdução}

Em face da insistente e predatória afirmação do mercado em âmbito global, regional e local, o Estado-nação passa por um processo revisório de suas funções, em sua qualidade de sustentáculo regulatório do direito em suas múltiplas dimensões.

Direito $^{1}$ e mercado ${ }^{2}$ sempre tiveram uma relação estreita e complicada. De certa forma estamos diante de uma profunda contradição, posto que o direito - tal como o esporte, o lazer, a cultura, a educação, a religião etc. - insiste em pressupostos nobres fundantes e sustentadores; entretanto, depende diretamente de fomento financeiro para sua manutenção, relação por vezes negada, ou pelo menos minorada, enquanto fator ou efeito determinante.

A questão de fundo consubstancia-se em verificar a possibilidade da relação/ interação direta entre direito e mercado, enquanto categorias de análise, conservando-se suas naturezas distintas e intocadas ou enquanto faces da mesma realidade. Seria crível fixar o grau de ingerência entre eles? Ou, ainda, é razoável a convivên-

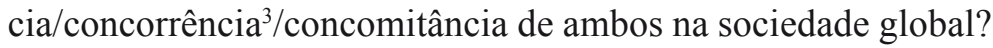

O mercado, institucionalizado pelos ordenamentos dos Estados e suas respectivas Constituições (Grau, 2004, 111-112), reclama sua sobrevivência e legalidade/ legitimidade na falácia da garantia jurídica, bem como na desregulamentação regulada $^{4}$. Imperioso é saber o papel do Estado-nação, se é que existe, enquanto regulador/gestor do mercado no âmbito de seu território e de suas relações globais conseqüentes.

Que fique clara, já nesta altura, nossa suspeição acerca da capacidade e vocação do Estado-nação como gestor do mercado. Seu afastamento gradual da con-

\footnotetext{
${ }^{1}$ Entendemos, neste texto, o direito enquanto categoria positiva, visto que é o direito positivado que se apresenta na atualidade com maior grau de concentração de eficácia legal, sem excluir outras acepções conseqüentes enquanto relação subordinada. O que não pretendemos, neste momento, é nos lançar numa discussão conceitual altamente interessante mas fora do propósito deste trabalho.

${ }^{2}$ Entendemos a categoria de mercado numa perspectiva conseqüente do processo político e econômico da globalização. Trata-se da transformação do capitalismo enquanto interdependência dos mercados financeiros numa dimensão global e seus efeitos na economia de mercado. Numa palavra, observase uma perda significativa da soberania econômica dos Estados nacionais e sua migração gradual e aprofundadora para o sistema financeiro global. Para Ulrich Beck (1998), trata-se de uma perspectiva específica denominada de Globalismo enquanto ideologia do domínio do mercado mundial, fruto do liberalismo em sua forma economicista de redução à dimensão monocausal da realidade.

${ }^{3}$ No sentido de concorrer para o mesmo fim.

${ }^{4}$ Sobre esta discussão, ver ALMEIDA, Fernando Dias Menezes. Considerações sobre a "regulação" no direito positivo brasileiro. In: Revista de Direito Público da Economia. PDPE, ano 1, n. 1, jan/ mar. Belo Horizonte: Fórum, 2003, p. 69-94. O autor situa a problemática da regulação na atualidade com grande lucidez e objetividade.
} 
dução de processos de mercado, porém, tem produzido as mais diversas distorções, não das finalidades deste, mas do Estado Democrático de Direito previsto na Constituição Brasileira de 1988, com fulcro no art. $1^{\circ}$, inciso IV, combinado com o art. 170 , e subordinados hermeuticamente ao inciso III do art. $1^{\circ}$ e ao art. $6^{\circ}$. É sabida a proposta conciliatória da Constituição de 1988 entre valores sociais do trabalho e economia de mercado - isto deve ser compreendido, todavia, como concessão sujeita a controle principiológico do Estado Democrático de Direito, numa perspectiva ideológica/programática/teleológica/conciliatória/regulatória.

Algumas dessas questões permitem complexas e específicas digressões, que não são possíveis neste texto, ainda mais por não acreditarmos em visões compartimentadas e estanques no campo científico. Não obstante, prevalece a idéia da possibilidade, ou não, de interação/subordinação dialética destes fenômenos e dos riscos a que ambos estão expostos nessa interação.

As intersecções entre direito e mercado podem ser percebidas como reflexo da intensificação do neoliberalismo na qualidade de instrumento econômico-político. O Estado-nação passa por mutações de ordem substancial em sua condição de comunidade política, adaptando-se à nova ordem de mercado global ${ }^{5}$.

A economia de mercado, instrumento do capital financeiro global, altera o centro decisório político, antes concentrado no Estado-nação, transferindo-o para o sistema financeiro internacional - e não apenas restringindo seu grau de interferência, mas sobretudo delimitando e subordinando suas finalidades de gestão ${ }^{6}$.

\section{Perspectiva metodológica}

Entendemos as propostas teóricas de Pierre Bourdieu como instrumental metodológico ${ }^{7}$ ideal, não-excludente, para captação do campo direito/mercado, sobretudo a íntima interação entre a visão bourdieusiana e a teoria de Max Weber enquanto matriz analítica.

\footnotetext{
${ }^{5}$ Remetemos os interessados nesta questão aos textos de DUPAS, Gilberto. A lógica econômica global e a revisão do Welfare State: urgência de um novo pacto. In PEREIRA, Luiz Carlos Bresser; WILLEIM, Jorge; e SOLA, Lourdes (org.). Sociedade e estado em transformação. São Paulo: UNESP; Brasília: ENAP, 1999, p. 219-232. Ver também FARIA, José Eduardo. O direito na economia globalizada. São Paulo: Malheiros, 2002.

${ }^{6}$ Veja a recente queda da bolsa em Xangai (27/02/2007), que, combinada com a retração na economia americana, provocou um forte impacto nas bolsas de todo o mundo.

${ }^{7}$ Consideramos por instrumental metodológico a noção de método enquanto forma analítica da realidade. Para isto, ver DEMO, Pedro. Metodologia científica em ciências sociais. 3. ed. São Paulo: Atlas, 1995.
} 
A categoria do tipo ideal é o principal instrumento metodológico em Weber para estabelecer o significado cultural dos fenômenos, assim como para formular proposições empíricas sobre eles (SAINT-PIERRRE, 1994, 67).

Conceitos genéricos, tipo ideal, conceitos genéricos de estrutura típico-ideais, idéias no sentido de combinações de pensamento que influem empiricamente nos homens históricos, tipos ideais dessas idéias, ideais que dominam os homens, tipos ideais desses ideais, ideais a que o historiador refere a história, construções teóricas com utilização ilustrativa do empírico, investigação histórica com utilização de casos-limite ideais, enfim, as mais diversas complicações possíveis, que apenas pudemos aqui assinalar - tudo são construções ideais cuja relação com a realidade empírica do imediatamente dado é, em cada caso particular, problemática. Esta lista diminuta demonstra já o constante entrelaçamento dos problemas metodológicos e conceituais que continuamente se encontram no campo das ciências da cultura. E visto que nos limitamos aqui a nos referir aos problemas, vimo-nos obrigados a renunciar ao aprofundamento das questões de metodologia e a discutir com pormenores as relações entre o conhecimento de tipo ideal e o obtido por 'leis', entre os conceitos de tipo ideal e os conceitos coletivos, etc. (WEBER, 1993, 127).

Numa perspectiva supra-histórica, Weber busca analisar a realidade a partir dos tipos ideais, encontrando nos tipos puros de dominação um mecanismo para tentar taquigrafar a realidade histórica:

Dominação Racional é aquela baseada na crença na legitimidade das ordens estatuídas e do direito de mando daqueles que, em virtude dessas ordens, estão nomeados para exercer a dominação legal; a dominação Tradicional é baseada na crença cotidiana da santidade das tradições vigentes, desde sempre, e na legitimidade daqueles que, em virtude dessas tradições, representam a autoridade; e a dominação Carismática como aquela baseada em veneração extracotidiana, da santidade, do poder heróico, ou do caráter exemplar de uma pessoa e das ordens por esta revelada ou criada. (WEBER, 1991, 141).

Em todos os tipos de dominação é mote a legitimidade da autoridade, posto que Weber muitas vezes usa os termos "autoridade" e "dominação" como sinônimos. Importante salientar que os tipos de dominação estão sujeitos a combinações (mesclagem) entre si, o que dificulta sua análise objetiva, implicando necessariamente fragmentações na incursão da realidade. 
Não que se entenda como menos importante a abordagem realizada por outros autores ${ }^{8}$, mas nossa principal finalidade é a apreciação da dicotomia direito/ mercado, em contraposição a pontos de vista delimitados pela necessidade circunstancial - sem, obviamente, impossibilitar qualquer discussão reflexa.

Bourdieu (1987) traz lume à nossa proposta com a conceituação de habitus enquanto conjunto de esquemas de classificação da realidade que se interiorizam pelos mais diversos processos estruturados e estruturantes relacionados às práticas e regularidades de conduta; e de campo, que por sua vez é estruturado pelas posições sociais, derivadas de leis e regras próprias, ou seja, estrutura de relações objetivas; derivadas do poder simbólico, invisível e proveniente da cumplicidade entre os que o exercem e os que a ele se submetem.

O direito e o mercado, assim como outras formas de poder simbólico, na condição de processos de dominação funcionam de modo próprio e com características específicas, enquanto modos de produção da sociedade. O direito, o mercado, a religião, a família, a escola etc. operam numa sociedade concreta e determinada, existindo uma clara relação entre direito/mercado na procura, produção e consumo de bens, incidindo numa relação transacional, ou seja, a produção de legalidade/ legitimidade.

Pode-se inferir da realidade direito/mercado o ensejo de produção de bens simbólicos, diretamente relacionados à estrutura social, com forte tendência à re-

\footnotetext{
${ }^{8}$ Veja-se a visão do materialismo histórico, onde poder se define pela dominação de classe. Para o marxismo é a posse ou a disposição dos meios de produção, e a capacidade ou não de controlá-los, que determina a possibilidade de exercício do poder por uma classe social. Sua concepção de poder político decorre daí, sendo o Estado considerado, no marxismo clássico, como a instituição em virtude da qual uma classe dominante e exploradora impõe e defende seu poder e privilégios contra a classe ou classes que domina e explora. Também merece destaque a proposta de Foucault, que, apesar de não estabelecer uma teoria geral sobre o poder, inclui o tema de forma privilegiada em sua construção teórica. Para ele, não há poder que designe alguma essência, existindo apenas relações de força que constituem situações de poder. O poder não pode ser circunscrito ou setorizado apenas ao econômico, pois seus mecanismos, efeitos, relações e dispositivos são exercidos em níveis diferentes da sociedade, e em domínios com extensão variada (FOUCAULT, 1979, p. 174). Assim, reduzir a questão do poder ao econômico, ao direito, ao Estado e a seus aparelhos, é empobrecer sua natureza. Na Microfísica do poder, Foucault traz sua concepção geral sobre o poder - que pode ser vista, enquanto instrumento metodológico, em todas as suas obras, sobretudo na História da sexualidade (1976) e em Vigiar e punir (2003), que traz seu ponto de vista do fenômeno da dominação. Mas deve-se levar em conta que a interpretação de Marx e do marxismo são muito distintas, e reduzir sua concepção do poder às questões econômicas é igualmente limitar uma teoria tão abrangente. Devemos considerar que Foucault tem outras matrizes à sua disposição, sobretudo a teoria da dominação de Max Weber. Por isso sua concepção do poder é mais latente que patente e não admite concepções unívocas do poder. Foucault conseguiu ampliar o marxismo - que o influenciou decisivamente, numa concepção mais lata dos elementos difusos do poder, que não se reduzem ao econômico, mas admitem também sua dimensão. Trata-se, portanto, de uma (re)leitura de Marx sob a problemática de Weber.
} 
produção da conjuntura social, altamente regulada pela estrutura interna do campo direito/mercado - e, este, estruturado/estruturante.

Para garantir a permanência da dominação, Bourdieu (1999) ressalta o trabalho de eternização competente a instituições interligadas que concorrem para garantir a perpetuação das relações de dominação, ou seja, igreja, Estado, escola, o direito, o mercado etc.

Enquanto instrumento da justiça, o direito é um mito que funciona como processo de dominação. Assim como as classes, a religião, a família etc., o mercado e o direito se servem de processos de dominação e legitimação (domínio das mentes).

Nas palavras de Bourdieu (2000, p. 11):

É enquanto instrumentos estruturados e estruturantes de comunicação e de conhecimento que os < $<$ sistemas simbólicos $>$ cumprem a sua função política de instrumentos de imposição ou de legitimação da dominação de uma classe sobre outra (violência simbólica) dando o reforço da sua própria força às relações de força que as fundamentam e contribuindo assim, segundo a expressão de Weber, para a 'domesticação dos dominados'.

E ainda:

O poder simbólico, poder subordinado, é uma forma transformada, quer dizer, irreconhecível, transfigurada e legitimada, das outras formas de poder: só se pode passar para além da alternativa dos modelos energéticos que descrevem as relações sociais como relações de força e dos modelos cibernéticos que fazem delas relações de comunicação, na condição de se descreverem as leis de transformação que regem a transmutação das diferentes espécies de capital em capital simbólico e, em especial, o trabalho de dissimulação e de transfiguração (numa palavra, de eufemização) que garante uma verdadeira transubstanciação das relações de força fazendo ignorar-reconhecer a violência que elas encerram objetivamente e transformando-as assim em poder simbólico, capaz de produzir efeitos reais sem dispêndio aparente de energia. (BOURDIEU, 2000, p. 15)

O que nos parece é que, no campo direito/mercado e numa linguagem bourdieusiana, procede-se a uma regulação pela estrutura social das relações de dominação. Naturalmente devemos levar em conta a diversidade de tratamentos possíveis à temática, em face das múltiplas formas de dominação afeitas ao fenômeno jurídico e ao próprio mercado. Tanto direito como mercado, em sua qualidade de sistemas simbólicos, funcionam como princípio de estruturação que constrói a experiência, graças ao efeito de legalidade/legitimação. 
Por se tratar de sistemas simbólicos de representações estruturados e estruturantes, a capacidade e a acumulação jurídica e de mercado nas suas mais diversas expressões - no âmbito do direito: leis, sistemas conducentes, poderes etc., no âmbito do mercado: concorrência, marketing empreendimento etc. - operam como elementos legitimadores e produtivos do habitus direito/mercado, interiorizando os valores classificatórios referentes à legalidade, legitimidade, referência, segurança jurídica e econômica, sendo o habitus determinante como referência para classificação social na estrutura do campo direito/mercado, que, para Bordieu (1987), se apresentam como derivados do poder simbólico invisível e da cumplicidade entre os que o exercem e os que a ele se submetem.

\section{Direito e mercado: um novo ethos desencantado}

Uma das sugestões possíveis para captação do fenômeno direito/mercado é o evidente processo de mercantilização do direito e a sacralização do mercado.

A religião, dada sua confusão com o Estado em boa parte da história da humanidade, contribuiu de forma direta e determinante para o aparecimento tardio do processo de secularização. $\mathrm{O}$ direito, enquanto elemento intrínseco ao mercado e considerando suas relações com a religião, pode ser percebido em várias tradições do passado. Verifiquemos alguns exemplos como referência para nossa análise.

Em Israel, século VIII a.C., Amós profetizou que as vacas de Basã - mulheres dos ricos comerciantes israelitas - estavam condenadas por sua relação de consumo desenfreada, que se processava a partir da exploração do pobre e necessitado, legitimadas na religião judaica enquanto elemento do Estado secular. Amós foi repreendido duramente pelos profetas oficiais, por contrariar a doutrina oficial do rei e dos profetas de seu círculo íntimo. O discurso da pós-modernidade talvez não resistisse a um novo Amós.

$\mathrm{Na}$ Grécia antiga podemos ver a relação direito/Estado/religião de forma cristalina na literatura de Sófocles, sobretudo em "Antígona". Os poderes do Rei Creonte são diretamente questionados pela tradição religiosa que se funda na consciência e proporciona uma das mais complexas e inadiáveis questões da humanidade: a solução do conflito Jurídico fruto da discussão da legalidade versus a legitimidade da lei; do conflito Moral, onde a solução sempre empenha a consciência do homem que torna o direito eficiente por seu fundamento; e do conflito Político, que questiona os limites do poder do Estado, sua natureza e razão finalística, pressupondo o mesmo como guardião do direito positivo na condição de garantia do direito natural.

Duas outras obras retratam tal problemática: $O$ martelo das feiticeiras, escrito em 1484 pelos inquisidores Heinrich Kramer e James Sprenger, e $O$ nome da 
rosa, obra de 1983 de autoria de Umberto Eco. De certa maneira, o que está em jogo são as relações religiosas como instrumento do direito político, e a questão de mercado. Nos dois clássicos existe uma imbricação tênue: $O$ martelo das feiticeiras representou um manual de repressão contra a mulher e o prazer, mas sobretudo contra a concorrência no mercado simbólico, em suas mais diversas perspectivas; O nome da rosa, que conta a história de assassinatos ocorridos num mosteiro beneditino da Idade Média, demonstra a problemática das relações de poder mercadológico jurídico/religioso.

A religião foi o principal instrumento de legitimação de diversos processos: religiosos, por certo, mas também políticos, morais, filosóficos etc. Mais tarde a religião perdeu espaço para a ciência e, depois, para a tecnologia. Evidentemente a perda de espaço fez a religião recrudescer sob múltiplas formas e relutar na permanência como via mercadológica privilegiada de compreensão paradigmática da realidade, e não poucas vezes de maneira viril, autoritária e arbitrária.

Questões como aborto, sexo, controle de natalidade e eutanásia, dentre outras, ainda são centrais e determinantes em algumas sociedades, apesar da insistência em declarar esses temas como pertencentes à esfera do Estado laico, sobretudo no ocidente. Veja-se o caso do referendo português sobre a interrupção voluntária da gravidez, que teve lugar em 11 de fevereiro de 2007: muitos sustentaram e ainda sustentam uma posição contrária à descriminalização do aborto a partir de fundamentos religiosos, nada tendo a ver com o direito penal. Parece que o Estado continua umbilicalmente ligado à religião.

A sacralização do mercado teve início com a modernidade ${ }^{9}$, afirmou-se com o surgimento do capitalismo em escala mundial, a partir do século XIX, e atingiu seu ápice na pós-modernidade ${ }^{10}$.

\footnotetext{
${ }^{9}$ A modernidade surge de forma preponderante a partir do século XVI, traduzindo-se como uma nova forma de compreensão da realidade enquanto ruptura. O fenômeno da modernidade é reflexo de uma conjunção de fatores confluentes: o humanismo renascentista, o renascimento, a reforma protestante, a revolução científica, a descoberta do novo mundo etc., que propiciaram uma nova acepção de mundo e da realidade a partir da idéia de progresso, valorização da subjetividade do indivíduo, da razão como foro privilegiado de autoridade, dentre outras, proporcionando uma releitura da cultura, das artes, da religião etc.

${ }^{10}$ De forma direta e mesmo simplificadora, visto não ser objetivo deste trabalho a análise das diversas propostas de se entender este fenômeno, pode-se dizer que se trata de um processo multifacetado que se desenvolveu a partir da segunda metade do século XX, reflexo da multiplicidade (ou multiplicação) e aceleração dos mais diversos fatores e influências: comunicação, informação, arte, arquitetura, cinema, tecnologia, cultura de massa, economia etc. São fatores confluentes culturais, históricos, religiosos, sociais, políticos, econômicos etc. Fruto da crise da modernidade, na qualidade de receptáculo de um ethos de progresso e emancipação, a pós-modernidade apresenta-se, sobretudo na segunda metade do século XX, como resultado do desencanto e da perda de credibilidade em relação às grandes metanarrativas desenvolvidas ao longo da modernidade e que propugnavam, idealisticamente, o progresso
} 
A inserção do direito no campo mercadológico se reveste de secularização, contrapondo-se ao dito propósito de justiça como fundamento, enquanto reflexo das sociedades racionalizadas ${ }^{11}$.

A secularização e, por conseguinte, a dessacralização da cultura e o respectivo desapego à tradição, reflexo do processo produzido pela modernidade, propiciaram o desencantamento do mundo, uma vez que a relação com o sagrado inverteu seu eixo central. Até o século XVI o mundo era encantado, fruto direto da intervenção divina em todas as áreas da vida privada e pública - apesar da ausência de hegemonia plena da Igreja medieval.

Desde a modernidade, as concepções sobre o direito, o Estado e o mercado têm se aprofundado numa perspectiva irreversível, se é possível que isto se dê em qualquer realidade. O Estado-nação, sustentáculo do direito positivo, passa por um processo de (re)definição ontológica e teleológica. Seus elementos constitutivos tradicionais, concebidos e sustentados desde Maquiavel, Hobbes, Locke e Rosseau, sofrem efeitos tanto da bipolaridade, presente até o declínio da URSS, como da unipolaridade política atual ${ }^{12}$.

da verdade, o conhecimento e a razão emancipatória. A pós-modernidade se caracteriza exatamente pela pluralidade, diversidade e fragmentação. Segundo Lyotard (1979), a pós-modernidade é reflexo do próprio esgotamento da ilusão moderna e posterior visão iluminista. Perry Anderson (1998) apresenta-nos um panorama da problemática pós-moderna, especialmente na contraposição dos principais expoentes à época. Destacam-se dentre os principais analistas do fenômeno, seja por sua afirmação, seja pela negação, Michel Foucault, Jacques Derrida, Jean-Francois Lyotard, Gilles Deleuze, Jürgen Habermas e Perry Anderson. Na área específica do direito merece olhar atento a contribuição de André-Jean Arnaud e Maria José Dulce Farinãs. Importante salientar a contradição inerente à suposta pós-modernidade, a diversidade de opiniões, bem como seus riscos para os países periféricos, onde boa parte da população, ainda em condições pré-modernas, é conservada à margem dos benefícios tecnológicos, nas mais diversas áreas. Assim, são preocupantes os efeitos da pósmodernidade, sobretudo para o direito constitucional, visto o desiderato de esvaziamento desconcentração - do poder das sociedades políticas locais, regionais e nacionais, e, conseqüentemente, a redução de elementos emancipatórios - direitos sociais, trabalhistas etc.

${ }^{11}$ Devemos levar em conta a grande diversidade de desenvolvimento (tecnológico, infra-estrutural, referente e direitos civis e políticos) que encontramos nas sociedades do século XXI. Existem sociedades em estágios muito diferentes de desenvolvimento, desde o mais alto grau de concentração tecnológica e de respeito aos direitos civis e políticos, até nações marginalizadas com poucas ou nenhuma destas conquistas. Usualmente se difere entre países desenvolvidos, subdesenvolvidos e em desenvolvimento; ou ainda em centrais e periféricos, categorias matizadas e usadas como critério ligeiramente etnocêntrico. Também é importante salientar que no interior dos Estados existe uma grande diversidade de processos culturais, econômicos, tecnológicos e políticos, absolutamente distintos, contraditórios e concomitantes nas mais diversas regiões.

${ }^{12}$ Vivemos sob a falaciosa armadilha da ausência de contraponto político entre capitalismo e socialismo, combinada com a inoperância das organizações internacionais, sobretudo a ONU, a qual, sofrendo de ausência de representatividade/legitimidade, necessita urgentemente de reforma em seus estatutos por não corresponder à realidade presente, seja pela carência de pressupostos históricos originais, seja pela deficiência de elementos sustentadores finalísticos.

Revista Seqüência, no 56, p. 177-204, jun. 2008. 
Percebe-se uma profunda alteração na compreensão do direito, culminando com a crise de (re)afirmação do Estado-nação e, nomeadamente, com a compreensão do direito constitucional como movimento reflexo dos processos emancipatórios do direito, na condição de realidade social.

Este processo de desenraizamento produz uma (re)definição conceitual em todos os ramos do direito, a começar pelo direito constitucional, em face de uma nova ordem global perigosamente desintegradora do local e exigente de novas categorias analíticas. O direito constitucional passa por um processo nunca dantes visto, tendo seus pressupostos de validade, necessidade e legitimidade constantemente questionados no que tange a sua efetividade.

Um exemplo é a experiência brasileira da Constituição de 1988 e sua mudança de eixo. Inspirada no modelo português de constitucionalismo pós-revolucionário (1976), a Carta viu sua perspectiva econômica dirigente sucumbir, sendo transformada em mera norma programática. A lição de Bercovici e Massonetto (2006, p. 71) é altamente esclarecedora:

A ordem econômica intervencionista e dirigente da Constituição de 1988 é isolada de seus instrumentos financeiros, cuja efetividade é medida em si mesma, sem qualquer relação com os objetivos da política econômica estatal ou da ordem econômica constitucional. A implementação da ordem econômica e da ordem social da Constituição de 1988 ficaram restritas, assim, às sobras orçamentárias e financeiras do Estado.

Caminho diverso trilhou o Constitucionalismo português, que a partir de 1976 passou por um longo processo de metamorfose, para usar o sentido proposto por Vital Moreira (2006, p. 34), na relativização do significado original socialista em que foi concebido e se adaptar à economia de mercado e à perspectiva programática do Estado regulador, sobretudo pela necessidade de adequação às exigências da Comunidade Econômica Européia.

Parecem irrefutáveis o processo insistente da politização do direito constitucional e, em contrapartida, a acelerada desjuridicização constitucional. O que se indaga, portanto, é se o direito e, de forma muito sintomática, o direito constitucional, estão perdendo espaço para o mercado enquanto sistema simbólico da pósmodernidade, ou se trata do (re)descobrimento do próprio direito enquanto projeto de sobrevivência e/ou instrumento regulatório.

Recentemente trava-se uma discussão sobre a conveniência ou não - e, portanto, o fim ou não - das Constituições dirigentes enquanto instrumento emancipatório e catalisador dos ideais a ser realizados pela sociedade e pelo Estado. Esse não é o objeto principal de nossa análise, mas não se pode deixar de reconhecer sua impor- 
tância, sobretudo por questões de ordem relacional com o direito/mercado, em face da nova ordem jurídica que submerge/emerge na atualidade.

A problemática, nos parece, deve ser vista a partir não mais da conveniência ou não da permanência de pressupostos dirigentes nas Constituições, mas da constatação de novas categorias da análise para o Estado-nação enquanto sustentáculo de cartas constitucionais dirigentes e vice-versa ${ }^{13}$, como as novas formas de Estado em processo de (de)formação/(re)afirmação no século XXI, notadamente com sustentação vinculante do Estado-nação. Para isto nos parece adequada a lição de Lenio Streck ${ }^{14}$ : "Há, efetivamente, um abismo separando o discurso sobre a Constituição da efetiva operacionalização/concretização do Direito Constitucional" (STRECK, 2004, p. 302).

E ainda:

Parece evidente, assim, que, quando se fala em Constituição dirigente, não se está - e nem se poderia - sustentar um normativismo constitucional (revolucionário ou não) capaz de, por si só, operar transformações emancipatórias. O que permanece da noção de Constituição dirigente é a vinculação do legislador aos ditames da materialidade da Constituição, pela exata razão de que, nesse contexto, o Direito continua a ser um instrumento de implementação de políticas públicas. (STRECK, 2004, p. 334)

Em face de uma nova ordem, que sofre os efeitos de processos desintegradores e perversos da globalização, emerge a questão dos direitos humanos, do meio ambiente e do direito penal ${ }^{15}$, as quais transcendem as categorias de análise tradicionais do Estado-nação na condição de elemento catalisador e receptáculo dos direitos individuais e transindividuais. Grün (2006) considera esta problemática central en-

13 Sobre esta questão, ver CANOTILHO, José Joaquim Gomes. "Brancosos" e interconstitucionalide: itinerários dos discursos sobre a historicidade constitucional. Coimbra: Almedina, 2006; e COUTINHO, Jacinto Nelson de Miranda (org.). Canotilho e a Constituição dirigente. Rio de Janeiro/São Paulo: Renovar, 2003.

${ }^{14}$ Streck (2004, p. 333), em sua propugnada Teoria da Constituição dirigente adequada a países de modernidade tardia, propõe "uma interligação entre teoria do Estado, visando à construção de um espaço público apto a implementar a Constituição em sua materialidade. Dito de outro modo, uma tal teoria da Constituição dirigente não prescinde da teoria do Estado". A perspectiva do autor parece coincidir com a opinião de Morais (2002, 91-92), para quem a modernidade, enquanto sustentáculo do Estado-nação, não se exauriu na pós-modernidade, hipótese sustentada, dentre outros, por Jürgen Habermas.

${ }^{15}$ Reportamos-nos aqui ao direito penal em sua tendência de internacionalizar e institucionalizar os crimes contra a humanidade, sobretudo pela incapacidade de o Estado-nação lidar com esta problemática tendo em vista que normalmente os autores praticam este tipo de crime no exercício do poder público ou em sua função. 
quanto reflexo da globalização na atualidade, adotando um enfoque sistêmico e cibernético dos fenômenos jurídicos como proposta metodológica.

Neste diapasão e como via de mão dupla da desterritorialização dos direitos humanos e das Constituições, Morais (2002, p. 89) entende tratar-se "de um processo que podemos chamar de internacionalização do direito constitucional que se complementa pela internalização/constitucionalização do direito internacional público (Direitos Humanos)".

Este nos parece ser o núcleo duro de materialidade constitucional a que todas as outras questões, inclusive a dos possíveis processos de implementação de uma nova ordem constitucional transnacional, devem subordinar-se enquanto princípio hermenêutico. O problema de fundo e mediato de maior importância é a necessidade de atualização epistemológica, metodológica e paradigmática envolvendo a releitura do direito constitucional num referencial crítico e interdisciplinar, tendo os direitos humanos, o meio ambiente e o direito penal como categorias de análise do próprio direito, na função de instrumental regulatório ${ }^{16}$ na sociedade pós-moderna.

Assistimos na pós-modernidade ao desencantamento e, conseqüentemente, à perda de importância e relevância do direito constitucional, do valor jurídico, da religião, da família, dos valores etc., enquanto categorias de resolução de conflitos numa dimensão micro/macro.

Neste sentido nota-se uma contradição da sociedade pós-moderna. De um lado há um profundo desencantamento nos/dos processos de solução de conflitos "oficiais", como o direito positivo e seus instrumentos, o Estado-nação e os organismos internacionais; de outro, o surgimento de novas-velhas religiões com new roupagem, novas e criativas formas de terrorismo, novos atores sociais como o Terceiro Setor ${ }^{17}$ etc. Contraditoriamente, grupos de representação que reivindicam maior abrangência, como o Fórum Social Mundial e o Fórum Econômico Mundial, insistem em agendas concorrentes e não-confluentes sobre a temática da conciliação entre capital e trabalho.

\footnotetext{
${ }^{16}$ Acolhemos a sugestão de Chevallier (2003), pela qual a regulação funciona nas sociedades contemporâneas de maneira associada a elementos teleológicos, numa estreita ligação com a governança meio de legitimação dos poderes estabelecidos e motor de mudança política -, visto prevalecer a noção de conjunto e, portanto, de superação de concorrência do poder pela confluência de interesses.

${ }^{17}$ Trata-se dos mais diversos setores organizados da sociedade civil - culturais, empresariais, educacionais, fundações, etc. -, locais e globais, tais como entidades civis, organizações não-governamentais, organizações patronais, profissionais e trabalhadores. Ver FRANCO, Augusto. Reforma do Estado e do Terceiro Setor. In: PEREIRA, Luiz Carlos Bresser, WILHEIM, Jorge e SOLA, Lourdes (org.). Sociedade e Estado em transformação. São Paulo: UNESP; Brasília: ENAP, 1999, p. $273-$ 289.
} 
Evidencia-se um desencantamento com o papel e sobretudo com as finalidades do Estado-nação, podendo-se dizer que há um descompasso entre a tentativa de (des)regulamentação jurídica observada na atual conjuntura - dado o alto grau de racionalização burocrática nas sociedades nacionais - e a completa impotência de controle do Estado-nação nos processos de mercado local/global (des)regulamentado e, por conseguinte, do direito em sua pretensão regulatória e gerencial como resolução de conflitos. O resultado é o mercado cada vez mais presente e, em conseqüência, (des)regulador das mais diversas relações, e seus efeitos muito mais agudos num direito constitucional crescentemente (des)regulamentado. A pós-modernidade enquanto processo cultural (re)civilizatório impõe uma (re)definição de papéis e significados e, destarte, do direito constitucional, expressão mais significativa do sujeito coletivo denominado Estado-nação.

Paradigma desta resistente conjuntura, o direito constitucional está agonizando e subtraindo-se de ser sujeito para tornar-se objeto. Não seria oportuno perguntar se estamos diante de sua derrocada ou sua (re)afirmação? Ou, ainda, se haverá lugar para a Constituição, ou mesmo para o Estado-nação no sentido clássico, na nova conjuntura global? Resistirá o Estado-nação à barbárie do mercado e à despolitização/desconstitucionalização da economia?

A própria discussão sobre o fim das Constituições dirigentes, contrapondo românticos, idealistas, realistas e céticos (se é possível estabelecer lados) - cada qual com suas mútuas contribuições -, é um sintoma imanente deste novo ethos emblemático referencial de materialidade jurídica.

A necessidade de concorrência e/ou sobrevivência tem produzido as mais variadas guinadas e adaptações do direito ao sabor do mercado, com a mesma inversa conseqüência de adaptação conveniente do mercado aos estatutos legais do Estado-nação. No dizer de Fiori (apud Bercovici, 2005, 5), "para isso promoveu-se a despolitização radical das relações econômicas, com a fragilização dos sindicatos, partidos políticos e Parlamentos, reduzindo-se a vida democrática ao mínimo necessário".

\section{Globalização e direito constitucional}

Como necessidade/sobrevivência/conveniência, a politização do direito constitucional remete inevitavelmente à questão da globalização enquanto processo inerente às sociedades pós-modernas, sobretudo e inexoravelmente pelo domínio da cena política por parte das forças transnacionais do mercado (FALK, 1999).

O impacto da globalização resulta no enfraquecimento do Estado-nação e, portanto, de seus elementos constitutivos tradicionais, produzindo uma “ordem só- 
cio-econômica de natureza cada vez mais multifacetada e policêntrica" (FARIAS, 2002, p. 15).

Longe de encontrar uma definição consensual, dadas as muitas variáveis envolvidas nesta polissêmica controvérsia conceitual, parece-nos prudente a perspectiva de Giddens (1991, p. 64), pela qual a globalização se consubstancia na "intensificação crescente das relações sociais e comunicações supra-regionais mundializadas, com reflexos profundos na reprodução dos sistemas político-jurídicos territorialmente segmentados em forma de Estado".

Giddens (2002, p. 221) também estabelece que a reorganização do tempo e do espaço acarreta uma profunda relação de desencaixe, produzindo um deslocamento das relações sociais dos contextos locais e sua (re)articulação através de partes indeterminadas - espaço-tempo, possibilitando uma situação de reflexibilidade institucional.

Santos (2005, p. 85) define globalização como “conjuntos de relações sociais que se traduzem na intensificação das interacções transnacionais, sejam elas práticas interestatais, práticas capitalistas globais ou práticas sociais e culturais transnacionais". A proposta do autor se condiciona à compreensão da existência de um fenômeno multifacetado.

Segundo Ulrich Beck, o fenômeno da globalização comporta dimensões distintas, mas intimamente relacionadas. Beck diferencia três tipos de dimensões no fenômeno:

Por Globalismo entiendo la concepción según la cual el mercado mundial desaloja o sustituye al quehacer político; es decir, la ideología del dominio del mercado mundial o la ideología del liberalismo. Esta procede de manera monocausal y economicista y reduce la pluridimensionalidad de la globalización a una sola dimensión, la económica (...). (1998, p. 27)

La Globalidade significa lo siguiente: hace ya bastante tiempo que vivimos en una sociedad mundial, de manera que la tesis de los espacios cerrados es ficticia. No hay ningún país ni grupo que pueda vivir al margen de los demás. (...) Así, 'sociedad mundial' significa la totalidad de las relaciones sociales que no están integradas en la política del Estado nacional ni están determinadas a través de ésta. (1998, p. 28)

Por su parte, la Globalización, significa los procesos en virtud de los cuales los Estados nacionales soberanos se entremezclan e imbrican mediante actores transnacionales y sus respectivas probabilidades de poder, orientaciones, identidades y entramados varios. (1998, p. 29) 
Existe uma interdependência entre as distintas globalizações e, deste modo, não podem ser reduzidas a apenas uma dimensão. Encontramos na proposta de Globalismo de Beck liame privilegiado em nossa proposta de análise, nomeadamente pela irrupção deste modelo subordinatório do Estado-nação e seu documento político delimitatório/programático essencial, a Constituição, aos desígnios do mercado.

Ora, entendemos o processo de globalização, em suas possíveis dimensões (SANTOS, 2005, p. 26), numa lógica de inclusão e não de exclusão de efeitos. Isto significa o caráter dinâmico da vida social pós-moderna, numa dialética local/global, alterando todas as relações: intimidade versus publicidade, com conexões de grande amplitude.

Cabe lembrar Otavio Ianni (1999, p. 239): “A idéia de globalização faz-se presente ainda que a palavra não seja empregada e se pense em termos de nação. Este é um momento epistemológico fundamental: o paradigma clássico, fundado na reflexão sobre a sociedade nacional, está sendo subsumido formal e realmente pelo novo paradigma, fundado da reflexão sobre a sociedade global”.

As mudanças não atingiram somente a economia, mas também as formas tradicionais de Estado e direito, mediante o esvaziamento progressivo do Poder Legislativo em prol de uma organização corporativa de poder que se processa por meio de agências da administração, tendo em vista os vários setores do capital. Este processo de desencaixe legal, produto da crise do Estado-nação, está produzindo um redimensionamento da concepção jurídica e política das cartas políticas. Caminhamos para uma crise constitucional, reflexo da impotência do Estado-nação em gerenciar a legalidade/legitimidade na sociedade global, tendo em vista o deslocamento do eixo do poder jurídico estatutário dos contratos sociais tradicionais para estatutos supranacionais.

De acordo com Habermas (1995, p. 99), os Estados são cada vez menos capazes de controlar suas economias nacionais. O raio de ação das políticas econômicas, financeiras e sociais vem, entretanto, se reduzindo drasticamente, inclusive na área fiscal, fruto da circulação de mercadorias que traz superávit para a balança comercial dos países, numa dependência de um mercado globalizado. Para o autor, a comunicação global ocorre tanto por meio de linguagens naturais (na maioria das vezes por meios eletrônicos) como por códigos especiais (é o caso, sobretudo, do capital e do direito). Deste processo decorrem duas tendências opostas: de um lado se promove a expansão da consciência dos atores (individuais ou coletivos); de outro, à diferenciação e ampliação dos sistemas, redes (como mercados) ou organizações. 
Este panorama, longe de ser irrealista, é apenas uma possibilidade dentre muitas outras. Por isso Habermas (1995, p. 100) propõe a necessidade da emergência de regimes supranacionais com o formato da União Européia: "Precisamos salvar a herança republicana, mesmo que seja transcendendo os limites do Estado-nação. Nossas capacidades para a ação política devem acompanhar o ritmo da globalização, das redes e sistemas auto-regulados". Habermas (1995, p. 101) entende que todas as sociedades já constituem parte inseparável de uma comunidade de riscos compartilhados, que são percebidos como desafios para uma política cooperativa.

A posição de Habermas sobre a União Européia não encontra ressonância em outros autores, sobretudo Amaral (2006), para quem o projeto de integração européia não possui chances de concretização enquanto possibilidade de conjunção entre federalismo político e neoliberalismo econômico, sugerindo um caminho alternativo confederal/regulador para a sonhada concepção federal/neoliberal.

A globalização, no que tange a sua natureza e enquanto processo, implica três elementos teóricos constitutivos distintos, intrinsecamente relacionados e com efeitos concomitantes e reflexivos: econômico, político e cultural.

$\mathrm{O}$ vértice econômico se deve à existência de necessidades em maior grau de bens adequados para sua satisfação. Numa economia de produção em larga escala no sentido externo e interno, fruto da necessidade de equilíbrio na balança comercial e de pagamentos, surge o problema das barreiras alfandegárias, controle de tributos, acordos aduaneiros etc., em um mercado internacional que necessita das mais diversas organizações e organismos interlocutórios e/ou regulatórios.

Importante destacar que a internacionalização da economia sob formas subordinadas a interesses externos coloca novos e graves problemas para os países subdesenvolvidos e em desenvolvimento, tornando-se muito difícil uma postura independente e isolacionista.

O fenômeno da globalização econômica produz uma inevitável reflexão a respeito do papel da Constituição e da dificuldade de sua operacionalização enquanto documento programático político, jurídico e social do Estado-nação.

No Brasil seus efeitos são tão contundentes que impediram a aplicação de uma norma constitucional desde a promulgação da Constituição Brasileira de 1988. Referimos-nos ao emblemático parágrafo $3^{\circ}$ do artigo 192, que denegava a cobrança de juros de $12 \%$ ao ano, apesar da perspectiva notadamente programática (MIRANDA, 2005, p. 151), por vezes destituída de aplicabilidade. Depois de reiteradas decisões, onde se pacificou tratar de norma de eficácia limitada (Súmula STF 648), condicionando sua aplicabilidade à edição de lei complementar, o STF pôs fim às discussões no julgamento da $\mathrm{ADIn}^{\circ} \mathrm{4} / 2003$, apesar de posições contrárias abalizadas no próprio tribunal e na doutrina (SILVA, 2003, p. 803), e de que comportava 
a admissibilidade do mandado de injunção (BARROSO, 2003, p. 765-766), dada a ocorrência de mora legislativa em razão da não-edição de lei necessária a sua eficácia (BARROSO, 2003, p. 97). O parágrafo foi revogado pela Emenda Constitucional $\mathrm{n}^{\circ} 40$, de 29/05/2003, que funcionou de fato como uma desconstitucionalização do sistema financeiro nacional (MORAES, 2006, p. 754).

Também em Portugal verificou-se a retração dos elementos econômicos emancipatórios pós-revolução de 1974, originalmente inseridos na Constituição aprovada em 1976 e curiosamente preservados no preâmbulo, certamente como um perfume histórico inspirador para as novas gerações.

No âmbito cultural houve nas últimas décadas um forte enriquecimento, motivado pela grande quantidade de informações, sobretudo pelos meios de comunicação e por esta ferramenta e/ou instrumento assustador: a internet. Os valores passaram a circular de forma automática e em tempo real, possibilitando o surgimento de influências mundiais e criando-se uma terceira cultura, ao lado da local e da nacional: a global. Observa-se a convergência de símbolos culturais e das formas de vida globais nas mais diversas influências locais e regionais, ocorrendo ainda uma maior assimilação da cultura global nas sociedades ocidentais, sobretudo nas grandes metrópoles (BECK, 2004, p. 71).

Em seu aspecto político/jurídico, tão premente quanto o econômico e o cultural, o que se questiona é a soberania dos Estados nacionais e a perda de sua influência, qual receptáculo primordial dos elementos subjacentes aos direitos da cidadania e representatividade política da individualidade/coletividade. Os elementos constitutivos do Estado-nação estão em risco, sobretudo após a invasão do Afeganistão e do Iraque pelos EUA, inaugurando a era da guerra preventiva, que a nosso ver fortalece, às avessas, o Estado-nação enquanto sustentáculo da soberania territorial, com sua autodeterminação subjacente e introjetada.

A sociedade global, no que tange aos benefícios, não atinge todas as pessoas, pois enquanto que alguns falam em tempo real com seus amigos e pessoas no mundo todo, os mendigos e marginais dormem ao relento ou embaixo das marquises dos prédios. O desenvolvimento tecnológico nem de longe atinge a grande maioria dos cidadãos, designadamente nos países periféricos, e ainda agrava a exclusão social. O mundo global não é monolítico, pois está atravessado por diversidades e desigualdades, nacionalismos e fundamentalismos, blocos regionais e imperialismos (IANNI, 2000, p. 26). Marx responderia que a relação Capital versus Trabalho não está resolvida, dadas as incoerências inerentes ao processo, sobretudo pelo aprofundamento da concentração de riquezas nos países ricos, e a dificuldade de solução de contradições como o terrorismo e sua contra-ideologia, a grande produção industrial e a não-distribuição de seus efeitos, a necessidade de ações afirmati- 
vas e de reforço ao direito das minorias/maiorias, bem como a um meio ambiente saudável, ao desenvolvimento sustentável, à distribuição de renda etc.

Se por um lado observa-se alto grau de desenvolvimento tecnológico, aliado ao mercado transnacional - que transfere diariamente mais de um trilhão de dólares sem nenhum controle dos bancos centrais, em um espaço global encolhido pelos instrumentos de comunicação nunca dantes visto -, por outro aprofunda-se a polarização entre pobres e ricos em uma dimensão galopante - cerca de 3,2 bilhões de pessoas, ou $60 \%$ da humanidade, sobrevivem à margem da sociedade, com uma média de 350 dólares/ano. No Brasil, 1\% das famílias mais ricas aufere $17 \%$ da renda do país, enquanto os $50 \%$ mais pobres, ou aproximadamente 80 milhões de pessoas, detêm cerca de 12\% (DOWBOR, 2000, p. 11).

A globalização, longe de um fenômeno homogêneo e linear, é altamente contraditória e paradoxal, face a seus resultados aprofundadores e definidores das diferenças entre ricos e pobres, mormente por sua visão predatória e subordinatória, para não dizer seletiva, imperante na sociedade global.

Paul Hirst e Grahame Thompson (1998) vêem na globalização um processo perverso e não acreditam que por bases econômicas haja realmente uma economia globalizada, estabelecendo que a "globalização" tem funcionado como um "mito" conveniente para os governos locais se isentarem de responsabilidade pelo que ocorre de negativo na economia e a transferirem ao âmbito das forças "supranacionais" fora do seu controle. Para os autores, os mercados até podem ser internacionais, mas a riqueza e a prosperidade econômica ainda são fenômenos nacionais e o Estado-nação, portanto, continua imprescindível na atual conjuntura global, a fim de garantir uma coalizão distributiva.

Ainda o pensamento de Milton Santos (2003), como contraponto à globalização que se tornou ideologia, afirma que se trata de fenômeno reversível, indicando uma esperança baseada no próprio esgotamento dos efeitos da globalização e na recriação da necessidade, dentro de um mundo de coisas e serviços abundantes, tendo como conseqüência a ampliação da consciência.

A despeito de seu perverso processo de concentração econômica e tecnológica, que implica um grave aprofundamento da miséria, a globalização parece ser, pelo menos momentaneamente, um fator inevitável. Mas não definitivo.

\section{Constituição: Resistir é preciso, viver não é preciso}

Com efeito, julgamos fundamental a resistência às demasiadas tentativas de estabelecer tipos puros e definitivos - "delimitatórios", numa perspectiva weberiana 
- para questões como terrorismo, nacionalidade, local, regional, nacional, global, Estado, modernidade, pós-modernidade etc.

A proposta (re)definitória de globalização de Falk (1999) é altamente crítica e sugestiva. Ao invés de apenas lamentar o processo necessita-se (re)encaminhá-lo a outros propósitos. Assim, Falk considera a existência de dois tipos de globalização:

Como Globalização descendente, um conjunto de forças e de perspectivas legitimadoras situado, em vários aspectos, fora do alcance efectivo da autoridade territorial que alistou a maioria dos governos como parceiros tácitos (1999, p. 221) e por globalização ascendente, um conjunto de reações de oposição no seio do terceiro sistema de activismo social. (1999, p. 233)

E ainda:

Por outras palavras, a globalização ascendente não se opõe dogmaticamente à globalização descendente, mas rege-se pelo princípio de evitar os efeitos adversos e de garantir um contrapeso global à influência fundamentalmente não controlada exercida actualmente pelo sector comercial e financeiro sobre o processo de decisão ao nível do Estado e fora dele.

É uma oxigenação do Estado-nação que precisa ser fortalecida pela democracia participativa e não-contemplativa, sobretudo pelo risco de transferência conveniente de responsabilidades da cidadania para o Ministério Público, como no caso brasileiro - o que, longe de contribuir para a democracia, produz efeito contrário e desastroso. Nem de longe questionamos a tão importante atuação do Ministério Público nas mais diversas áreas, mas é preciso uma postura de convergência de interesses, não de transferência ou de concorrência, especialmente nas questões do meio ambiente, direitos humanos e cidadania. A omissão da sociedade civil brasileira tem lançado o Ministério Público à condição de alvo útil das mais diversas investidas por parte daqueles que tem maior interesse em sua intimidação e limitação.

É essencial e urgente um maior aprofundamento das parcerias entre Poder Público e setor privado, da mesma forma que entre Poder Público, Ministério Público e sociedade civil - como já acontece em muitos setores -, numa redefinição de papéis que transcenda a tradicional visão policialesca do Estado, de um lado, e a visão exploradora do setor privado, de outro. Isso para que a missão relacional da sociedade leve em conta a proposta programática da Constituição Federal de 1988, mormente pela necessidade e urgência de participação de uma cidadania responsável em seus aspectos mais profundos, programáticos e pragmáticos - qual seja, uma ação coerente e norteada pelos institutos da democracia direta, na inspiração da globalização ascendente acima descrita. 
A convergência de interesses difusos se dá no interior do Estado-nação como interlocutor/mediador entre a sociedade civil local e a sociedade civil global. No dizer de Falk (1999, p. 252):

O Estado continua a ser o ponto crítico de charneira dessa luta, embora não se trate, nem mesmo no momento presente, de uma questão de oposição intrínseca entre o Estado como instrumento da globalização descendente e os movimentos sociais como instrumentos da globalização descendente. Em vários contextos específicos, estão a emergir alianças entre os Estados e movimentos sociais, como se torna evidente em relação a diversas questões relacionadas com o ambiente, o desenvolvimento e os direitos humanos.

Se há uma realidade inafastável na atual conjuntura global é a da necessidade de o Estado moderno conviver com um pluralismo jurídico-político e comunitárioparticipativo que emerge de novos "sujeitos coletivos" (organismos e organizações internacionais, representações as mais diversas). Sem mencionar o fato de encontrar-se em crise o paradigma jurídico do positivismo kelseniano monista, sobretudo no Brasil, com suas constantes crises institucionais que questionam a capacidade normativa e integradora do Estado-Institucional.

Sob os efeitos do contexto global, o Estado-nação passa por um processo de redefinição de natureza contratual, produzindo a desfiguração das constituições enquanto documentos político-jurídicos e alterando seus elementos essenciais constitutivos. Procede-se à (re)definição do papel das Constituições à realidade regional em que os Estados estão cada vez mais inseridos, ou deveriam, no que acreditamos consubstanciar importante fator de resistência à atual conjuntura globalizante.

Neste sentido é fundamental repensar o papel das Constituições enquanto componentes condicionantes e estruturantes para a (re)construção do ethos do Estado nacional numa sociedade transnacional e global de riscos compartilhados, dominado pela lógica do mercado, pela cultura do consumo e pela indústria do entretenimento (ADORNO; HORKHEIMER, 1985).

No entanto, merece olhar atento a leitura apressada, para não dizer míope, da pretensa exclusão do Estado-nação como mediador e gerenciador das relações sociais. Carece ponderar, de um lado, sobre a insuficiência e ineficiência do Estado interventor e centralizador, uma vez que já está condensada a idéia de sua incompetência gerencial ortodoxa ${ }^{18}-\mathrm{e}$, de outro, a precariedade da pretensa declaração de seu óbito e substituição, pelo mercado, de suas funções primárias. Este prognóstico

${ }^{18}$ Referimo-nos à gestão autoritária e não-partícipe da sociedade. 
parece demasiadamente precipitado, ou ao menos sombreado da realidade, numa perspectiva platônica. Não há neste momento melhor interlocutor entre a sociedade e mercado que o Estado-nação, este configurado como gestor/articulista por meio do direito, sobretudo o direito constitucional, capaz de evitar a ilusão pragmática dirigente, para não dizer inconseqüente, e oxigenar as relações sociais nas mais diversas acepções, em sua difícil (re)afirmação de contratualismo social.

A lição de Chevallier (2005, p. 145) parece elucidar o fio condutor de nossa análise e intenção:

Assim concebida, a governança constitui um modelo de exercício do poder de aplicação geral, transponível para todos os níveis e em todas as esferas de organização social. Correlativamente, a lógica da governança tende a penetrar o conjunto do direito, tanto privado como público: a idéia de que convém associar os diferentes atores à elaboração da norma e preferir o consenso à coerção é atualmente comumente admitida. Em todos os níveis, os produtores de direitos são convidados a se conformar aos preceitos de governança. Isso não significa, no entanto, que se esteja em presença de uma configuração jurídica radicalmente nova. De um lado, esses preceitos já estavam mais ou menos presentes no direito clássico, como demonstra a existência de procedimentos consultivo e contratual. Por outro lado, o 'direito de governança' não rompe com os cânones da dogmática jurídica, como o atesta a perpetuação das formas jurídicas tradicionais. O direito de governança não deve, portanto, ser percebido como um substituto ao direito clássico: na realidade, a governança 'associa, segundo modalidades infinitas, direito 'duro' (hard law), escrito, com efeitos claros, e direito 'mole' (soft law), móvel, evolutivo. E mesmo quando ele afeta o direito existente, ela sempre fica sob o império de sua racionalidade. Finalmente, a lógica da governança pode também contribuir à consolidação dos princípios jurídicos tradicionais: a 'boa governança' pregada pelas instituições financeiras internacionais para os países em desenvolvimento implica, não o menosprezo de tais princípios, mas maior atenção às garantias jurídicas, através da intensificação das exigências do Estado de direito. A boa governança vem, assim, reforçar a ortodoxia jurídica.

Este fenômeno vem sendo designado como Constitucionalismo Moralmente Reflexivo (CANOTILHO, 2006, p. 125-129), o qual, consciente da dificuldade do Estado garantista, identificador de Constituição/Estado, propõe uma nova leitura do constitucionalismo à luz da nova ordem global, sustentado na "superação do esquema paradigmático Constituição-Estado; a necessidade de ultrapassar as teorias de 'momentos constitucionais' isolados e únicos e apreender o sentido e limites do chamado 'constitucionalismo evolutivo'; a substituição do esquema hierárquiconormativo do direito constitucional por um sistema multipolar de 'governance' constitucional" (CANOTILHO, 2006, p. 283). 
O que parece coerente é não perder o foco de um constitucionalismo atualizado e contextual, aberto (HÄBERLE, 2002) e sustentado pela concepção do Estadonação enquanto articulador e garantidor de elementos essenciais dos documentos políticos, tais como os direitos humanos, o meio ambiente etc., perfazendo um núcleo de identidade, num sentido antropológico, que permita a vinculação dos poderes públicos e da ordem social/econômica em geral à materialidade constitucional.

Este núcleo de identidade funciona como ethos de resistência constitucional, que, ao contrário de entender que uma Constituição não deve ser alterada substancialmente, a considera um instrumento de seu tempo e que deve, portanto, traduzir a realidade na qual está inserida. Dito de outra forma, não há razão para uma Constituição fora do tempo (LASSALE, 2001), sob risco de enrijecimento normativo e, por conseguinte, ineficaz, e nem de mudança inconseqüente, sob risco de desfiguração (HESSE, 1991).

Em sua proposta hermenêutica de Constituição, Peter Häberle (2002) oferece alternativa interessante aos modelos aparentemente conflitivos de Hesse e Lassale. Ele propõe uma interpretação da Constituição centrada no modelo aberto e pluralista de sociedade. Para Häberle não é possível a limitação de intérpretes da Constituição numa sociedade plural. Não está em jogo a supressão de jurisdição, mas a oferta de legitimidade à legalidade como reflexo da democracia.

Acreditamos que o constitucionalismo brasileiro está sob insidiosa encruzilhada. Aceita a idéia de uma Constituinte ou resiste-se a ela - o que será o mais provável enquanto reserva de mercado aos políticos -, permanecendo alienada e antitética. Não nos atreveríamos a sugerir uma Constituinte ${ }^{19}$ - apesar de ser madura e oportuna a pretensão -, sobretudo pelas dificuldades formais, mas devemos reconhecer que a Constituição de 1988 sofre de crise de identidade, merecendo no mínimo uma terapia intensivo-profunda na busca das razões de desgaste de natureza e finalidade a que está sendo submetida; subsídios formais, materiais e históricos, portanto.

\footnotetext{
${ }^{19}$ Neste caso somos favoráveis a um Congresso exclusivo e, portanto, constituinte em sua essência, e não Congresso Constituinte como o que elaborou a Constituição de 1988. O tema converteu-se em debate através da imprensa, a partir de proposta inusitada feita por advogados ao presidente Lula, em agosto de 2006, com opiniões diversas e contraponto entre Ives Gandra da Silva Martins, pela defesa e sustentabilidade legal, e Dalmo Dallari, Elio Gaspari, Gilmar Mendes e Carlos Ayres Britto, dentre outros, pela insustentabilidade constitucional (Folha de São Paulo, 4 a 6 de agosto). A questão ocupa novamente a atenção pela proposta insidiosa da PEC 157, que pretende instalar uma Assembléia Constituinte Revisora, motivando protestos no seio da comunidade acadêmica, sobretudo pelos riscos ao Estado Democrático de Direito. Não entraremos na discussão da legitimidade do Congresso Nacional que elaborou a Constituição de 1988 por fugir aos objetivos deste trabalho, mas para elaboração de uma Constituição, em sua melhor lavra, somos partidários de um Congresso exclusivo e, portanto, constituinte em sua essência e não Congresso Constituinte, como foi o caso da elaboração da Constituição de 1988.
} 
É verdade que conservamos um núcleo duro de preceitos constitucionais garantistas por suas consistentes cláusulas pétreas, mas assistimos a sua desfiguração pelo instrumento legal -mas pouco coerente, a se pensar em suas finalidades essenciais - das Emendas Constitucionais. Essa desfiguração não ocorre apenas do ponto de vista formal, mas implica riscos materiais. Não se reforma, visto não existir tal instituto jurídico na previsibilidade constitucional brasileira em Portugal as reformas programadas cumpriram sua finalidade atualizadora, mas se desfiguram pelo visível processo de desregulamentação/descontitucionalização, que em última análise operacionaliza, de forma desregrada e destemperada, uma "reforma às avessas".

A questão premente é que o sujeito paradigmático do Estado constitucional mudou. O Estado-nação traveste-se de novas formas, merecendo uma (re)adequação constitucional à nova ordem, exatamente para salvaguardar-se em seu núcleo essencial diante dos novos sujeitos da ordem global, que, em preservando os aspectos essenciais das cartas políticas dos Estados, deverá atuar como interlocutor, articulador/moderador/regulador de estatutos mais abrangentes e eficientes para $\mathrm{o}$ tratamento de questões que transcendem as fronteiras tradicionais do Estado-nação, mormente àquelas ligadas aos direitos humanos (CANOTILHO, 2003, p. 1370), ao meio ambiente e ao direito penal.

Parece indicativa a necessidade de resistência do Estado-nação enquanto receptáculo dos interesses individuais e coletivos, nomeadamente os daqueles com menos acesso às políticas sociais e emancipatórias. A sociedade francesa continua paradigmática deste modelo de resistência tardia ${ }^{20}$ contra os "discursos liberalizantes das elites e sua práxis política (...) e por maiores garantias sociais por parte do Estado" (DUPAS, 1999, p.230).

\section{Considerações finais}

Concluindo, se possível, com a perspectiva de Benjamim (1995) - que reconhece a grave questão do capitalismo que impõe a cultura de massa, mas indica um tom mais positivo ao processo, pressupondo a sobrevivência da individualidade, com seus valores e práticas (BARROS FILHO; SÁ MARTINO, 2003, p. 200) - consideramos fundamental a sobrevivência do Estado-nação com sua Constituição, como contraponto político, jurídico, social e cultural à visão de mercado e legítimo operacionalizador/catalisador/regulador da cidadania local e global, entre a globalização e a sociedade.

\footnotetext{
${ }^{20}$ Por meio de referendo, França e Holanda votaram contra a Constituição Européia, colocando novo tempero nas pretensões de efetivação confederativa da Europa.
} 
Faz-se necessário e imperativo, a partir do Estado-nação como interlocutor, inverter o processo regulatório do mercado em favor dos interesses da sociedade. Trata-se de uma subordinação inversa, pois o mercado quer a institucionalização da (des)regulamentação enquanto garantia da fluência de suas relações, tanto contra o Estado como contra outros agentes econômicos (GRAU, 2004, p. 113). A proposta é de (re)construção fundante da sociedade política, adequada à aldeia global que, no dizer de Falk (1999, p. 233), proporciona uma íntima conjugação/correlação de esforços entre a sociedade civil local e a sociedade civil global (agentes de representatividade global, como ONGs, organismos transnacionais etc.). Somente a associação do Estado-nação com a sociedade civil pode evitar o retorno ao estado de natureza hobbesiano, principalmente se interagir com o Terceiro Setor, numa conjugação do global e do local (ARNAULD, 1999, p. 20).

O Estado-nação, na qualidade de recipiente mais amplo da categoria de poder institucionalizado, não deve renunciar à tarefa dirigente, mas "flexibilizar o estilo da ação pública, trazendo novas categorias de atores para elaboração das escolhas coletivas" (CHEVALLIER, 2003, p. 131), e sobretudo pela parceria e concorrência de interesses com o Terceiro Setor, "enquanto parceiro nas estruturas do poder e de coordenação" (SANTOS, 2006, p. 337).

Derradeiramente, faz-se imperiosa uma contraglobalização, pelo fortalecimento do Estado-nação enquanto legítimo representante da sociedade, atuando não como subordinado, mas como ator principal, ao lado da sociedade civil local e global, mormente por entender que à globalização não interessa o fim do Estado-nação, mas sua subordinação teleológica, posto que o mesmo, em sua atual conjuntura, além de não oferecer resistência, lhe serve como aliado ao processo de dominação legítima.

Com efeito, compete ao Estado-nação articulador/regulador/gestor a vigilância para evitar a gaiola de ferro da racionalidade imposta pelo capitalismo global. A resistência do Estado-nação enquanto receptáculo de nossas representações coletivas continua sendo a mais urgente e necessária utopia para transcender a sedução imediatista e efêmera do canto das sereias (ADORNO; HORKHEIMER, 1985, p. 44-45).

O grande risco é, no dizer de Adorno, o da Mínima Morália: ao jogar a água da bacia fora, jogar a criança.

Quem viver verá! 


\section{Referências}

ADORNO Theodor W.; HORKHEIMER Max. Dialética do esclarecimento. Rio de Janeiro: Zahar, 1985.

ALMEIDA, Fernando Dias Menezes. Considerações sobre a "regulação" no direito positivo brasileiro. In: Revista de Direito Público da Economia. PDPE, ano 1, n. 1, jan/mar. Belo Horizonte: Fórum, 2003, p. 69-94.

AMARAL, João Ferreira do. União Européia: o pós-federalismo. In: Boletim de Ciências Econômicas. ISSN 0870-4260, volume XLIX, Coimbra: Faculdade de Direito da Universidade de Coimbra, 2006, p. 79-95.

ANDERSON, Perry. As origens da pós-modernidade. Lisboa: Edições 70, 2005.

ARNAULD, André-Jean. O direito entre a modernidade e a globalização. Rio de Janeiro: Renovar, 1999.

.; DULCE, Maria José Farinas. Sistemas jurídicos: elementos para um análisis sociológico. 2. Edição. Madri: Universidad Carlos III: Boletín oficial, 2006.

BARROS FILHO, Clóvis; SÁ MARTINO Luís Mauro. O habitus na comunicação. São Paulo: Paulus, 2003.

BARROSO, Luis Roberto. Constituição da República Federativa do Brasil anotada. 4. ed. São Paulo: Saraiva, 2003.

BERCOVICI, Gilberto; MASSONETTO, Luís Fernando. A constituição dirigente invertida: a blindagem da constituição financeira e a agonia da constituição econômica. In: Boletim de Ciências Econômicas. ISSN 0870-4260, volume XLIX, Coimbra: Faculdade de Direito da Universidade de Coimbra, 2006, p. 57-77.

BECK, Ulrich. Qué es la globalización: falacias del globalismo, respuestas a la globalización. Barcelona: Paidós, 1998.

BENJAMIN Walter. Obras escolhidas III. São Paulo: Brasiliense, 1989. BOURDIEU, P. A Economia das trocas simbólicas. São Paulo: Perspectiva, 1987.

; A dominação masculina. Rio de Janeiro: Bertrand Brasil, 1999.

CANOTILHO, José Joaquim Gomes. "Brancosos" e interconstitucionalidade: itinerários dos discursos sobre a historicidade constitucional. Coimbra: Almedina, 2006.

Almedina, 2003.

; Direito constitucional e teoria da constituição. Coimbra: 
CHEVALLIER, Jacques. A governança e o direito. In: Revista de Direito Público da Economia. PDPE, ano 1, n. 1, jan/mar. Belo Horizonte: Fórum, 2003, p. 129-146.

COUTINHO, Jacinto Nelson de Miranda (org.). Canotilho e a constituição dirigente. Rio de Janeiro/São Paulo: Renovar, 2003.

DEMO, Pedro. Metodologia científica em ciências sociais. 3. ed. São Paulo: Atlas, 1995.

DOWBOR, Ladislau; IANNI, Otavio; RESENDE, Paulo-Edgar. Desafios da globalização. Petrópolis: Vozes, 2000.

DUPAS, Gilberto. A lógica econômica global e a revisão do Welfare State: a urgência de um novo pacto. In: PEREIRA, Luiz Carlos Bresser, WILHEIM, Jorge; SOLA, Lourdes (org.). Sociedade e Estado em transformação. São Paulo: UNESP; Brasília: ENAP, 1999, p. 219-232.

FALK, Richard. Globalização predatória: uma crítica. Portugal: Instituto Piaget, 1999.

FIORI, José Luís. Acumulação mundial e ingovernabilidade. In: BERCOVICI, Gilberto. O Estado de exceção e a periferia do capitalismo. In: NUNES, António José Avelãs (diretor). In: Boletim de Ciências Econômicas. ISSN 0870-4260, volume XLVIII, Coimbra: Faculdade de Direito da Universidade de Coimbra, 2005, p. 1-9.

FOUCAULT, Michael. Microfísica do poder. Rio de janeiro: Graal, 1979. GRAU, Eros. Mercado, Estado e Constituição. In: NUNES, António José Avelãs (diretor). In: Boletim de Ciências Econômicas. ISSN 0870-4260, volume XLVII, Coimbra: Faculdade de Direito da Universidade de Coimbra, 2004, p. 107119.

GIDDENS, A. Modernidade e identidade. Rio de Janeiro: Zahar, 2002. . As conseqüiências da modernidade. São Paulo: UNESP, 1991.

FARIA, José Eduardo, O direito na economia globalizada. São Paulo: Malheiros, 2002.

GRÜN, Ernesto. Las globalizaciones jurídicas. In: Revista Facultad de Derecho y Ciencias Políticas. vol. 36, n. 105. Medellín: Colômbia, JulioDeciembre, 2006, p. 323-338.

LASSALE, Ferdinand. O que é uma Constituição? Belo Horizonte: Editora Líder, 2001.

LYOTARD, Jean-François. A condição pós-moderna. 3. ed. Lisboa: Gradiva, 2003. 
HÄBERLE, Peter. Hermenêutica constitucional - sociedade aberta dos intérpretes da Constituição: contribuição para a interpretação pluralista e "procedimental" da Constituição. Trad. Gilmar Ferreira Mendes. Porto Alegre: 2002. HABERMAS, Jürgen. O Estado-nação europeu frente aos desafios da globalização. Revista Novos Estudos, n. 43, novembro de 1995, p. 87-101. HESSE, Konrad. A força normativa da Constituição. Trad. Gilmar Ferreira Mendes. Porto Alegre: Sérgio Fabris, 1991.

HIRST, Paul; THOMPSON, Grahame. Globalização em questão. Petrópolis: Vozes, 1998.

IANNI, Otavio. A política mudou de lugar. In DOWBOR, Ladislau; IANNI, Otávio; PAULO-EDGAR, A. Resende. Desafios da globalização. Petrópolis: Vozes, 2000.

1999.

. Teorias da globalização. Rio de Janeiro: Civilização Brasileira,

MIRANDA, Jorge. Teoria do Estado e da Constituição. Rio de Janeiro: Forense, 2005.

MORAES, Alexandre. Direito constitucional. 20. ed. São Paulo: Atlas, 2006. MORAIS, José Luis Bolzan. As crises do Estado e da Constituição e a transformação espacial dos direitos humanos. Porto Alegre: 2002.

SAINT PIERRE, H. L. Max Weber: entre a paixão e a razão. Campinas: Unicamp, 1994.

SANTOS, Milton. Por outra globalização. Rio de Janeiro: Record, 2003.

SANTOS, Boaventura Sousa. Os processos da globalização. In. SANTOS, Boaventura Sousa (org.). A globalização e as ciências sociais. 3. ed., São Paulo: Cortez, 2005, p. 25-102.

. A gramática do tempo: para uma nova cultura política. Porto:

Afrontamento, 2006.

SILVA, José Afonso da. Curso de direito constitucional positivo. São Paulo: Malheiros, 2003.

STRECK, Lenio Luiz. A concretização de direitos e a validade da tese da Constituição dirigente em países de modernidade tardia. In. AVELÃS, José Nunes; COUTINHO, Jacinto Nelson de Miranda (org.). Diálogos constitucionais: Brasil/Portugal. Rio de Janeiro: Renovar, 2004, p. 301-372.

WEBER, Max. Metodologia das ciências sociais. Trad. Augustin Wenet, 2. ed. São Paulo: Cortez; Campinas: Unicamp, Parte 1, 1993.

. Economia e sociedade. v. 1, trad. Regis Barbosa e Karem Elsabe Barbosa. Gabriel Cohn (rev. técnica). Brasília: UnB, 1991. 